\title{
FACTORS INFLUENCING THE EFFECTIVE CAPTURE OF INDIRECT COSTS IN ACCIDENT REPORTS BY EMERGING CONSTRUCTION CONTRACTORS IN SOUTH AFRICA
}

\author{
Ayodeji Olatunji AIYETAN ${ }^{1}$ and Chikezirim OKORAFOR ${ }^{2}$ \\ 1\&2Department of Construction Management and Quantity Surveying, Durban University \\ of Technology, Durban 4001 \\ Email: kezirim042@yahoo.com¹
}

\begin{abstract}
There has been limited research into the indirect cost of accidents in the South African construction industry, despite its consequences on productivity and performance measurement and management. Extant studies have attempted to explore the impact of direct and indirect costs from a macro-economic (industry-wide) perspective. Whilst a few have focused on the micro-economic impacts, with specific emphasis on the organizational level, most of these studies have concentrated on the construction client perspective without recourse to the experiences for construction contractors. This is the gap which this study seeks to fulfil within the South Africa. To achieve this objective, a document analysis of selected construction accident reports was conducted using a pre-set theme identified from the literature in extracting information from the emerging contractors 'accident reports. It was revealed that none of the reports were compliant as per the pre-set theme used. The reasons behind the non-compliance were sought for, through another round of data collection deploying semi-structured interview and questionnaire surveys. A population of contractors within CIDB grades 5-7 were interviewed and surveyed. Survey results revealed that difficulties in extracting the information top the list, followed by organisational will. Also, areas for improvement in capturing the accident report were highlighted such as; making it as a policy for any accident report to capture indirect cost and assigning timeliness on when the data must be captured in any accidents is paramount. This finding has implications on the emerging contractors as it provides information on factors that negate and impact on sustainability of the emerging contractors as it relates to OHS performance and competitiveness.
\end{abstract}

Keywords: Accident; Construction; Contractor; Cost; Health and Safety; South Africa

\section{INTRODUCTION}

The construction industry has been known to make significant contribution to economic development. Globally, the sector accounts for about $10 \%$ of gross domestic product (GDP), $7-10 \%$ of the GDP of developed countries and $3-6 \%$ in the case of under-developed countries (Murie, 2007; Giang and Pheng, 2011; Osei, 2013). In South Africa, the construction industry contributes about $4 \%$ to the GDP (Statistics South Africa, 2018a) and employs approximately $8 \%$ percent of the total labour force (Statistics South Africa, 2018b). Despite the salient contributions to economic and national development as highlighted previously, the high incidence of accidents within the industry makes it a dangerous industry (Kheni, Dainty, and Gibb, 2008; Sánchez, Peláez, and Alís, 2017). This industry has gained notoriety due to the excessive accident rates recorded on construction project sites (Brace and Gibb, 2005). Costs are associated with these accidents. Such costs which are categorised 
as direct and indirect costs are usually borne by various stakeholders to the construction project. According to Hinze (2006) and Hughes and Ferrett (2016), direct costs are those costs which are directly related to an accident. Examples of such costs include thetreatment of an injury and any compensation offered to injured workers, including hospitalisation and medical costs. On the other hand, Okorie and Smallwood (2010) and Griffin (2006), maintain that indirect costs comprise of costs emanating from, reduced productivity of injured worker(s), reduced productivity of workforce, costs resulting from delays, additional supervision costs, costs of clean-up after the accident, costs resulting from rescheduling of work to ensure timely completion, lost work days, and, training of new workers. The implications of such costs on the balance sheet of the relevant construction stakeholder are enormous as it reflects on the productivity and profitability of that stakeholder. Whilst extant studies have sought to ascertain the costs of accidents- direct and indirect- to the construction client within the South African construction landscape and beyond (Hughes and Ferrett, 2016, Haupt and Pillay, 2016), limited studies have considered the implications of indirect costs on emerging contractors. Emerging contractors are often described as small and medium enterprises with the potential to engender economic growth within national contexts. Unfortunately, such entities have been known to suffer from challenges like low profitability and productivity levels which render them unsustainable in the long term. This has affected the longevity of such firms. Obviously, understanding the implications of the indirect costs of accidents on the balance sheet of emerging contractors will contribute towards the development of effective protocols for managing same, thereby enabling better profitability levels. Yet, a cursory perusal of the accident reports prepared by emerging contractors highlights an emphasis on the reportage of direct costs, thereby neglecting the indirect costs. The skewed nature of reportage has a potential of negating the business sustainability of such firms considering the salient impact of indirect costs on their balance sheet. This study set out to ascertain the factors responsible for this underwhelming capture of indirect costs of accidents by emerging contractors in South Africa in their accident reports.

To achieve this objective, the rest of this paper is structured as follows; a review of relevant literature, a justification of the research method utilised, the presentation and discussion of findings and, a conclusion.

\section{LITERATURE REVIEW}

In South Africa, the construction industry contributes greatly to the statistics of employee injuries and deaths (Okorafor, Emuze and Das, 2016). These accidents cost the industry a lot of money because these injuries must be treated whilst productivity slows down due to shortage of personnel.A study conducted by Lingard (2013) indicates that at least 60,000 fatal accidents occur annually on construction sites globally. For example, in the United States, Orji, Enebe, and Onoh (2016) claim that this figure is increasing there-by costing the US economy severely in terms of lost workdays, compensation costs and lost productivity. Although the construction industry in the United Kingdom (UK) accounts for $5 \%$ of the total workforce, $22 \%$ of fatal injuries and $10 \%$ of reported major injuries are domiciled within this sector (Construction Health and Safety Group, 2018). In India, Kanchana, Sivaprakash, and Joseph (2017) revealed that Indian construction industry contributes $16.4 \%$ of fatal occupational accidents reported globally, despite having only $7.5 \%$ of the total world labour force. In Nigeria, the construction sector contributes $3.82 \%$ to the GDP of the economy (Okoye, Ezeokonkwo, and Ezeokoli, 2016). In South Africa; the situation is not different, according to reports by the Federated Employer's Mutual Assurance Company (2016).

Certain costs are associated with these accidents. Such costs impact negatively on the profitability or productivity of relevant construction industry stakeholders. According to the Occupational Safety and Health Administration OSHA (2017), the costs of accidents are 
divided into two categories: direct cost and indirect cost. Direct costs of accidents are usually considered those costs covered by workers compensation insurance and other minor medical costs for the accident while indirect costs are all the "uninsured" additional costs associated with an accident which are greater than direct cost (Us OSHA, 2017). The direct costs tend to be those associated with the treatment of the injury and any unique compensation offered to workers as a consequence of being injured (Hinze, 2006), and while indirect costs are those costs that are borne by contractors through: reduced productivity of both returned worker(s); legal fees for defense against claims; replacement costs for reworks; training costs for replacement of injured worker(s); costs of transportation to hospital, and wages paid while the injured is idle (Brauer, 2006).

Manuele (2011) posits that the disparity in the ratio of direct cost to indirect cost is worrisome. This disparity has considerable implications for construction industry productivity. According toChoi (2006), indirect costs are measured as being four times the direct costs whereas Heinrich, (1959) indicates that the indirect costs of injuries may range from two to 20 times the sum of direct costs. In corroboration to these assertions, the Western National Insurance (2010) estimates that the indirect costs are 3 to 10 times the direct costs of an accident. Similarly, the International Safety Equipment Association (ISEA, 2012), maintains that indirect costs are up to 30 times the direct costs. Brauer (2006) and Hinze (2006) identify costs of accident as having negative impacts on the productivity of the industry. However, in the study of Hinze (2006) and Manuel (2011) their findings suggest that indirect cost of accident are neglected which Haupt and Pillay (2016) espoused the reason behind it such as; organisational will, technical-know and difficulty in extracting such information. In extracting information on indirect cost of accident, Levit and Samelson (1987) and Griffin (2006), identified the following theme inter alia; cost of overtime work to make up for the resultant delays, administrative cost in terms of paperwork related to claims and reports, cost relating to orientation of the replacement workers, cost resulting from delays, additional supervision costs, transportation of injured workers, wages paid while injured worker/s was/were idle, reduction in productivity, cost of clean-up after the accident, cost of replacing material, plant and equipment, stand-by costs of idle plant and equipment (Levitt and Samelson, 1987; Okorie and Smallwood, 2010; Griffin, 2006).

The cost implications of these accidents are frequently cited as a major motivation for addressing construction H\&S (Hinze, 2006). Furthermore, Hinze (2006) describes construction accidents as a cancer afflicting the construction industry. According to the WHO (2010), over 1.25 trillion US dollars is spent annually on costs such as lost working time, workers' compensation, and medical expenses resulting in unsafe and unhealthy working conditions. This amount has negative economic implications on contractors. The economic burden of site accidents is a serious concern to all stakeholders and governments alike. From the business standpoint, site accidents and incidents affect the profitability of contractors. The WHO (2010) maintains that site accidents have forced many contractors particularly the emerging contractors into liquidation due to high compensation paid to the family of a deceased worker(s) or through a protracted legal litigation occasioned by site accidents. The motive of every organisation is to make profit, but when an accident occurs on site, it has both direct and indirect economic implications on the organisation.

The indirect cost affects their profit margins, which, in turn impacts on the national economy. The overall economic implications of construction site accidents and ill health to contractors are very significant and unacceptable. On the national scale, the estimated indirect costs of construction accidents can be as high as 7-10\% of a country's gross national product (ILO, 2011). Yet, little attention has been paid to tackling this phenomenon. Rather efforts have been dissipated on resolving the incidence of accidents on construction sites. For instance, in India, Kanchana, et al (2017) investigated the causes of accidents on construction sites while Okoye, Okolie, and Ngwu (2017) focused on the effectiveness of safety intervention and implementation strategies in Nigeria construction industry. Chileshe and 
Dzisi (2012) focused on the benefits of H\&S management in design organisations in the United Kingdom (UK). Alkilani, Jupp, and Sawhney (2013) identified factors hindering H\&S practice and improvement measures in the Jordanian construction industry. Okoraforet al (2016) looked at H\&S performance evaluation factors while Smallwood and Emuze (2016) looked at fatality, injuries, and diseases in the South African construction industry.

In the study context, an "emerging contractor" can be defined as a "person or enterprise which is owned, managed and controlled by previously disadvantaged persons and which is overcoming business impediments arising from the legacy of apartheid" (CIDB 2011). These enterprises are also termed "small construction enterprises" and "small-scale contractors". Emerging contractors are generally characterised by limited capital resources, plant and equipment, and managerial support, all of which affect their ability to acquire skilled labour and employ professionals (Eyiah 2001). This study, therefore, defines "emerging contractors" as: Small to medium contracting enterprises that are owned by individuals previously disadvantaged by the apartheid system of the pre-1994 South Africa and are registered with the CIDB grading of 1-7. The emerging contractor companies contribute significantly to economic growth and job creation in South Africa (Van Eeden et al 2003). The sector contributes approximately 67\% of employment opportunities in South Africa construction industry (Department of Trade and Industry, 2004). According to Pretorius (2009), 50-90\% of South African small businesses fail, $32 \%$ of which fail in the first seven years of operation (Nemaenzhe, 2010). Small business failure can result in financial losses (Shepherd et al 2009), loss of resources (Peacock 2000) and job losses (Argenti 1976; Van Witteloostujin 1998; Temtime and Pansiri, 2004). The high failure rate of emerging contractors in South Africa is of great concern (Muzondo and Mc-Cutcheon, 2018) and their slim profit margin which stands threatened by the non-consideration of many factors which includes indirect costs of accidents but not limited to. Yet several studies investigating emerging contractor financial sustainability and longevity have failed to take cognizance of this gap. Arguably, little attention has been given to indirect costs by these entities hence this study.

\section{RESEARCH METHOD}

The study utilised a pragmatic approach and the choice of pragmatism is premised on three main reasons, namely the nature of the research problem, the data and the methods of collecting this data, and the purpose of the research (Gray, 2014; Creswell, 2013). Based on the adoption of the pragmatist philosophical, the use of a simple mixed-method methodological choice was deemed most suitable for the study. The data collection was done in three phases: document analysis: to see if indirect costs were captured; Interviews: to ascertain the reasons behind the inability of Contractors to capture indirect costs and how to improve on it and; the questionnaire survey to evaluate the factors behind the poor capturing of indirect costs and the avenues for improving the present state of capture.

In the first phase, a comprehensive examination of construction accident reports prepared by emerging contractors in South Africa was undertaken to elicit information with a pre-determined set of criteria using thematic analysis. Sixteen accident reports from emerging contractors (CIDB grade 5-7) in South Africa were examined. This was premised on the availability and willingness of the contractor organizations to participate in the exercise. This indicates the use of convenience sampling in the selection of participating contracting organizations for the first phase of the study. For clarity sake, the themes utilized for extracting information from the report include; cost of overtime work to make up for the resultant delays, administrative cost in terms of paperwork related to claims and reports, cost relating to orientation of the replacement workers, cost resulting from delays, additional supervision costs, transportation of injured workers, wages paid while injured worker/s was/were idle, reduction in productivity, cost of clean-up after the accident, cost of replacing 
material, plant and equipment, stand-by costs of idle plant and equipment (Levitt and Samelson, 1987; Okorie and Smallwood, 2010; Griffin, 2006).

In the second phase, semi-structured interviews were conducted using a telephonic device to seek the reasons behind the findings emanating from the review of accident reports. The data obtained from the interview sessions formed the basis for phase 3 of the data collection exercise.

In phase 3, a questionnaire survey was administered to collect relevant data for establishing the most important factors militating against the capturing of indirect costs in construction accident report by South African emerging contractors. The questionnaire also sought to decipher the factors with the potential to contribute towards improving the capturing of indirect costs in construction accident report by emerging contractor organizations. A total of 1338 active contractors were listed as emerging contractors under CIDB grade 5-7 for General Building and Civil Engineering category (CIDB, 2015). Based on the target population as discussed above, the researchers used Slovin's formula with a margin of error of $5 \%$ to determine adequate number of sample:

$$
\mathrm{n}=\frac{\mathrm{N}}{1+\mathrm{N}}\left(\mathrm{e}^{2}\right)
$$

Where $\mathrm{n}=$ sample size, $\mathrm{N}=$ number of target population, $\mathrm{e}^{2}=$ margin of error. Based on the above formula, therefore the population is:

$$
\begin{aligned}
\mathrm{n}= & \frac{1338}{1+1338\left(0.05^{2}\right)} \\
\mathrm{n} & =307.9
\end{aligned}
$$

Three hundred and seven (307) questionnaires were distributed and two hundred (200) questionnaires were received from the emerging contractors across South Africa. Upon cleaning the data, 119 responses were found adequate and were used for the analysis. The data collected were analysed using descriptive statistics, particularly the Mean item score (MIS).

A five-point Likert scale was used to determine the factors militating the capturing of indirect cost in construction accident report. The adopted scale is as follows; $1=$ Most not important, $2=$ Not important, $3=$ Neutral, $4=$ Important and $5=$ Most important. The fivepoint scale was transformed to mean item score (MIS) for each of the factors of causes as assessed by the respondents. The indices were then used to determine the rank of each item. The ranking made it possible to cross compare the relative importance of the items as perceived by the respondents. The MIS was based on the previous studies conducted by (Sukamolson 2005) and Ayodele and Alabi (2011). This method was also used to analyse the data collected from the questionnaire survey. The computation of the relative mean item score (MIS) was calculated from the total of all weighted responses and then relating it to the total responses on an aspect. This was based on the principle that respondents' scores on all the selected criteria, considered together, are the empirically determined indices of relative importance. The index of MIS of a particular factor is the sum of the respondents' actual scores (on the 5-point scale) given by all the respondents' as a proportion of the sum of all maximum possible scores on the 5-point scale that all the respondents could give to that criterion. Weighting were assigned to each response ranging from one to five for the responses of 'Most not important 'to 'most important'. This is expressed mathematically below. The mean item score (MIS) was calculated for each item as follows, after Lim and Alum (2015).

MIS $=\frac{1 n_{1}+2 n_{2}+3 n_{3}+4 n_{4}+5 n_{5}-n_{5}}{\sum(N)} \frac{1}{2}$

Where, $\mathrm{n}_{1}=$ number of respondents for not important;

$\mathrm{n}_{2}=$ number of respondents for not important;

$\mathrm{n}_{3}=$ number of respondents for neutral; 
$\mathrm{n}_{4}=$ number of respondents for important;

$\mathrm{n}_{5}=$ number of respondents foremost important;

$\mathrm{N}=$ Total number of respondents

Following the mathematical computations, the criteria are then ranked in descending order of their mean item score (from the highest to the lowest).

\section{FINDINGS}

In this section, the findings from each of the phases will be presented according to the three phases discussed previously.

\section{Phase 1:}

\subsection{Document Analysis}

The accident reports were used to gather data on how construction accident report is captured among emerging contracting firms. This section introduces the details of the projects chosen, by providing the motivation for selection, the type of construction, and details of the project. Sixteen accident reports were examined as prepared by the contractors. The projects have been completed, and their accident reports are easily accessible. The reports were analysed to provide greater understanding of how indirect cost of accident have been captured. Table 1 provides an overview of the distribution of the reports analyzed.

Table 1: Overview of sixteen construction accident report

\begin{tabular}{|c|c|c|}
\hline Serial no & No of contractors/reports & Province \\
\hline $\mathbf{1}$ & 2 & Kwazulu-Natal \\
\hline $\mathbf{2}$ & 3 & Gauteng \\
\hline $\mathbf{3}$ & 2 & North West \\
\hline $\mathbf{4}$ & 2 & Western Cape \\
\hline $\mathbf{5}$ & 2 & Eastern Cape \\
\hline $\mathbf{6}$ & 2 & Free State \\
\hline $\mathbf{7}$ & 1 & Northern Cape \\
\hline $\mathbf{8}$ & 1 & Mpumalanga \\
\hline $\mathbf{9}$ & 1 & Limpopo \\
\hline
\end{tabular}

Source: Author Fieldwork, 2020

The selection was purposively done to get a glimpse of what is obtainable in the country. A total of 16 cases were examined, the study reveal that Kwazulu-Natal has 2 cases, Gauteng has 3cases, North West has 2, Western Cape has 2 cases, Eastern Cape has 2, Free State has 2 while Northern Cape, Mpumalanga and Limpopo has 1 case respectively. The description of projects ranges from high-rise residential buildings, government administrative building, schools, office parks, hospitals, and short-span bridges. Table 2 provides an overview of the application of the theme identified from the literature by the contractors.

Table 2: Application of the pre-set themes by the contractors

\begin{tabular}{|c|l|l|}
\hline $\begin{array}{c}\text { Serial } \\
\text { No }\end{array}$ & Identified pre-set theme & $\begin{array}{l}\text { Application of the theme by } \\
\text { the contractors }\end{array}$ \\
\hline 1. & $\begin{array}{l}\text { Cost of overtime work to make up for the resultant } \\
\text { delays. }\end{array}$ & $\begin{array}{l}\text { None of the contractors were } \\
\text { compliant }\end{array}$ \\
\hline 2. & $\begin{array}{l}\text { Administrative cost in terms of paperwork related to } \\
\text { claims and reports. }\end{array}$ & $\begin{array}{l}\text { None of the contractors were } \\
\text { compliant }\end{array}$ \\
\hline 3. & $\begin{array}{l}\text { Cost relating to orientation of the replacement } \\
\text { workers. }\end{array}$ & $\begin{array}{l}\text { None of the contractors were } \\
\text { compliant }\end{array}$ \\
\hline
\end{tabular}




\begin{tabular}{|c|l|l|}
\hline 4. & Cost resulting from delays in operation. & $\begin{array}{l}\text { None of the contractors were } \\
\text { compliant }\end{array}$ \\
\hline 5. & $\begin{array}{l}\text { Additional supervision costs for the replacement } \\
\text { workers. }\end{array}$ & $\begin{array}{l}\text { None of the contractors were } \\
\text { compliant }\end{array}$ \\
\hline 6. & $\begin{array}{l}\text { Transporting injured workers. } \\
\text { None of the contractors were } \\
\text { compliant }\end{array}$ \\
\hline 7. & $\begin{array}{l}\text { Wages paid while injured worker/s was/were idle } \\
\text { and reduction in productivity. }\end{array}$ & $\begin{array}{l}\text { None of the contractors were } \\
\text { compliant }\end{array}$ \\
\hline 8. & Cost of clean-up after the accident. & $\begin{array}{l}\text { None of the contractors were } \\
\text { compliant }\end{array}$ \\
\hline 10. & Cost of replacing material, plant and equipment & $\begin{array}{l}\text { None of the contractors were } \\
\text { compliant }\end{array}$ \\
\hline Stand-by costs of idle plant and equipment. & $\begin{array}{l}\text { None of the contractors were } \\
\text { compliant }\end{array}$ \\
\hline
\end{tabular}

Source: Author Fieldwork, 2020

The report examined shows that 13 out of the 16 cases have an accident report template by which data were captured. The remaining 3 cases did not have a standardized template for capturing accident data. The findings revealed that the accident report was not comprehensive to garner all the elements of indirect cost as required according to the identified pre-set themes which various authors have observed to constitute good practice (Levitt and Samelson, 1987; Okorie and Smallwood, 2010; Griffin, 2006). The study established that there was no clear-cut system for recording the indirect costs of accident in the reports. The following items were present in the reports analysed; date of accident, time of accident, specific area of accident, causes of accident, additional person involve, witness, accident descriptions, employee explanation of events, resulting action executed, planned or recommended. From these findings, it can be inferred that there is little or no possibility to derive the actual costs of accident from those reports. This can be attributed to the fact that there is no concerted effort made towards achieving the said objective which authors such as Levit and Samelson (1987) and Lutchman et al (2012) had highlighted impacts negatively on construction project performance. This observation further strengthens the proposition that accident reports do not consider the indirect and direct costs of accidents.

\section{Phase 2:}

\subsection{Semi-Structured Interview}

The interviews excerpts are from 5 contractors whose accident reports were examined formed the basis for this analysis. The interviewee's re-iterated factors that are hindering the capture of indirect cost of accident such as; no justification capturing indirect cost of accident in accident report; the industry lacks the organisational will to carry out such task which corroborate with the assertion made by Okorie and Smallwood (2010). Also factors such as; skills involved in extracting such information is lacking; contractor's negligence; ineffective OHS culture were also highlighted across the 5 interviewee's. Factors that can enhance the conditions were also elucidated such as; improving the use of such records in decision making in the organisation; training provision for personnel in charge for capturing such cost in which Levit and Samelson (1987) and Griffin (2006) considered as a good practice in managing the situation. The interviewee's concurred that insuring indirect cost of accident in any construction project will help to lessen the financial burden of the cost from the contractors. 


\section{Phase 3:}

\subsection{Questionnaire Survey}

The views of the respondents were assessed using Likert scale to measure the factors militating the capturing of indirect cost in construction accident report in South Africa and also factors that will help to improve the capturing of indirect cost in construction accident report. For clarity, the author's extracted information from the literature (Levitt and Samelson, 1987; Okorie and Smallwood, 2010; Griffin, 2006; Haupt and Pillay, 2016) and also a purposive snowball sampling techniques were deployed this necessitated the engagement of 5 interviewee's from the initial list of contractors whom their accident reports were analysed. The authors stopped at 5 interviews upon the attainment of data saturation and the information's was used for the preparation of the questionnaire.

The response rate is considered adequate given its similarity to the response rates associated with other surveys carried out within the same geographical and industry/sectoral context (Sutrisna, 2009; Okorie, Emuze and Smallwood, 2015). It can be inferred from Sutrisna (2009) and Danity (2008) that performing a statistical analysis in survey with a response rate equal to or above the threshold of thirty (30) is acceptable. Therefore, the $59 \%$ response rate achieved in this survey provides reasonable data for analysis. The data collected were analysed with the use of mean percentage and Mean item score (MIS).The respondents belong to different CIDB grades for example, $45 \%$ belongs to the CIDB grade 5, while $31 \%$ belong to CIDB grade 6 and $24 \%$ belong to the CIDB grade 7 .

An important feature in understanding the indirect cost of accident is the experience of the contractors within the construction industry. The average working experience of the respondents is 15 years. Table 3 suggests that majority of the respondents had reasonable working experience within the industry to contribute effectively to the study. $92 \%$ of the respondents had more than 5years in construction industry, $28 \%$ of whom had over 15 years of experience working in the industry.

Table 3: work experience of the respondents

\begin{tabular}{|l|c|c|}
\hline Years of experience & Frequency & Percentage \\
\hline $\mathbf{0}<\mathbf{5}$ & 9 & $8 \%$ \\
\hline $\mathbf{6}<\mathbf{1 0}$ & 37 & $31 \%$ \\
\hline $\mathbf{1 1 < \mathbf { 1 5 }}$ & 40 & $33 \%$ \\
\hline $\mathbf{1 6}<\mathbf{2 0}$ & 24 & $20 \%$ \\
\hline$>\mathbf{2 5}$ & 9 & $8 \%$ \\
\hline
\end{tabular}

Source: Author Fieldwork, 2020

Based on the ranking using the mean item score for the listed factors militating the capturing of indirect cost in construction accident report, according to the respondents the most important factors as shown in table 4 are as follows; difficulty in extracting the information $(\mathrm{X}=4.67 ; \mathrm{R}=1)$; organizational will $(\mathrm{X}=4.61 ; \mathrm{R}=2)$; construction practitioners don't make use of the data $(\mathrm{X}=4.45 ; \mathrm{R}=3)$; no justification of such exercise $(\mathrm{X}=4.39 ; \mathrm{R}=4)$; financial resources to carry out such task $(\mathrm{X}=4.37 ; \mathrm{R}=5)$; technical know-how ( $\mathrm{X} 4.30 ; \mathrm{R}=6)$; cost-benefit analysis $(\mathrm{X}=4.22 ; \mathrm{R}=7)$; bureaucracy bottleneck $(\mathrm{X}=4.19 ; \mathrm{R}=8)$; lengthy process in getting such data $(\mathrm{X}=4.13 ; \mathrm{R}=9)$; ignorance $(\mathrm{X}=3.98 ; \mathrm{R}=10)$; lack of transparency $(\mathrm{X}=3.72 ; \mathrm{R}=11)$; complacency on the part of the industry regulator $(\mathrm{R}=3.67 ; \mathrm{R}=12)$; management ineffective OHS culture $(\mathrm{X}=3.50 ; \mathrm{R}=13)$; awareness $(\mathrm{X}=3.22 ; \mathrm{R}=14)$; corruption $(\mathrm{X}=3.17 ; \mathrm{R}=15)$. 
Table 4: Factors militating the capturing of indirect cost in construction accident report

\begin{tabular}{|l|c|c|}
\hline Factors & MIS & Ranking \\
\hline 1. Difficulty in extracting the information & 4.67 & 1 \\
\hline 2. Organisational will & 4.61 & 2 \\
\hline 3. Construction practitioners do not make use of the data & 4.45 & 3 \\
\hline 4. No justification of such exercise. & 4.39 & 4 \\
\hline 5. Financial resources to carry out such task. & 4.37 & 5 \\
\hline 6. Technical know-how & 4.30 & 6 \\
\hline 7. Cost-benefit analysis & 4.22 & 7 \\
\hline 8. Bureaucracy bottleneck & 4.19 & 8 \\
\hline 9. Lengthy process in getting such data & 4.13 & 9 \\
\hline 10. Ignorance & 3.98 & 10 \\
\hline 11. Lack of transparency & 3.72 & 11 \\
\hline 12. Complacency on the part of the industry regulator & 3.67 & 12 \\
\hline 13. Management ineffective OHS culture & 3.50 & 13 \\
\hline 14. Awareness & 3.22 & 14 \\
\hline 15. Corruption & 3.17 & 15 \\
\hline Sourcerhor Fieldwork, & & \\
\hline
\end{tabular}

Source: Author Fieldwork, 2020

Table 4 indicates the extent to which the 15 factors identified hinder the capturing of indirect cost in South African construction industry in terms of MIS from 1.00 to 5.00.

From the evidence presented in Table 4, it can be seen that $60 \%$ of the factors have an MIS of $>4.00<5.00$, and can thus be deemed most important factors, thereby indicating their potential to hinder the capturing of indirect cost in accident reports within the South African construction industry to a great extent. The remaining $40 \%$ of the factors have MIS of $>3.00<4.00$ and can thus be deemed important factor as they hinder the process to a significant extent. From Table 4, it is evident that the factors that top the list are inter alia; difficulty in extracting the information; organizational will; construction practitioners' don't make use of the data; no justification of such exercise; financial resources to carry out such task; technical know-how, with mean item scores of 4.67, 4.61, 4.45, 4.39, 4.37 and 4.30 respectively.

These finding are worrisome, in the sense that the practitioners and the construction industry are been portrayed in negative light. There is evidence to suggest that construction stakeholders have pivotal roles to play in this regard as sustainable construction is paramount. The law empowered clients and their project consultants to pre-qualify contractors on H\&S performance competencies and oversee the implementation of H\&S plan on site (Gambatese, 2008; Lutchman, Maharaj and Ghanem; 2012; Laufer and Ledbetter, 2016). The consequences of these poor leadership and lack of commitment by clients and their project consultants result in such negligence (Hughes and Ferrett, 2010; ILO, 2018).

Based on the ranking using the mean item score for the listed factors that will help to improve the capturing of indirect cost in construction accident report, according to the respondents the most important factors as shown in table 5 are as follows; making it as a policy for any accident report to capture indirect $\operatorname{cost}(\mathrm{X}=4.82 ; \mathrm{R}=1)$; assigning timeliness on when the data must be captured in any accidents $(\mathrm{X}=4.66 ; \mathrm{R}=2)$; training provision for personnel in charge for capturing such cost $(\mathrm{X}=4.61 ; \mathrm{R}=3)$; developing a tool/template for capturing indirect cost in the industry $(\mathrm{X}=4.44 ; \mathrm{R}=4)$; improving the use of such records in decision making in the organization $(\mathrm{X}=4.25 ; \mathrm{R}=5)$; improving information on indirect costs and benefits in the area of OHS $(\mathrm{X}=3.99 ; \mathrm{R}=6)$; provision for funding for such exercise in any construction project $(\mathrm{X}=3.81 ; \mathrm{R}=7)$; insuring indirect cost of accident $(\mathrm{X}=3.76 ; \mathrm{R}=8)$; costbenefit analysis $(\mathrm{X}=3.64 ; \mathrm{R}=9)$; awareness creation regarding benefits of capturing indirect cost of accident ( $\mathrm{X}=3.33 ; \mathrm{R}=10)$; improving the OHS records $(\mathrm{X}=3.23 ; \mathrm{R}=3.23)$; creating a 
common database on indirect cost on occupational exposure to accidents and disease $(\mathrm{X}=3.03 ; \mathrm{R}=12)$.

Table 5: Factors that will help to improve the capturing of indirect cost in construction accident report

\begin{tabular}{|l|c|c|}
\hline Factors & MIS & Ranking \\
\hline 1. Making it as a policy for any accident report to capture indirect cost & 4.82 & 1 \\
\hline 2. Assigning timeliness on when the data must be captured in any accidents. & 4.66 & 2 \\
\hline 3. $\quad$ Training provision for personnel in charge for capturing such cost. & 4.61 & 3 \\
\hline 4. Developing a tool/template for capturing indirect cost in the industry & 4.44 & 4 \\
\hline 5. Improving the use of such records in decision making in the organisation. & 4.25 & 5 \\
\hline 6. Improving information on indirect costs and benefits in the area of OHS & 4.09 & 6 \\
\hline 7. Provision for funding for such exercise in any construction project. & 3.81 & 7 \\
\hline 8. Insuring indirect cost of accident & 3.76 & 8 \\
\hline 9. Cost-benefit analysis & 3.64 & 9 \\
\hline 10. Awareness creation (benefits of capturing indirect cost of accident). & 3.33 & 10 \\
\hline 11. Improving the OHS records & 3.23 & 11 \\
\hline 12. Creating a common database on indirect cost on occupational exposure to & 3.03 & 12 \\
\hline
\end{tabular}

Source: Author Fieldwork, 2020

Table 5 indicates the extent to which the 12 factors identified can improve the capturing of indirect cost in South African construction industry in terms of MIS from 1.00 to 5.00.

It is deduced that $50 \%$ of the factors have MIS of $>4.00<5.00$, and can thus be deemed most important factors, which indicates in general that they can improve the capturing of indirect cost in South African construction industry to a great extent. The remaining $50 \%$ of the factors have MIS of $>3.00<4.00$ and can thus be deemed important factor as they can improve the process to a significant extent. From Table 5 it is evident that the factors that top the list are inter alia; making it as a policy for any accident report to capture indirect cost; assigning timeliness on when the data must be captured in any accident report; training provision for personnel in charge for capturing such cost; developing a tool/template for capturing indirect cost in the industry; improving the use of such records in decision making in the organization; improving information on indirect costs and benefits in the area of OHS with mean item scores of 4.82, 4.66, 4.61, 4.44, 4.25 and 4.09 respectively. The study reveal that factors such as; making it as a policy for any accident report to capture indirect cost; assigning timeliness on when the data must be captured in any accident report; developing a tool/template for capturing indirect cost of accident in the industry and improving the use of such records in decision making in the organisation will engender sustainable practice and also improve construction project performance (Raftery, 2003; Siemiatycki, 2009).

\section{DISCUSSION OF FINDINGS}

This section comprises of the findings emanating from the two phases of data collection and analysis described in the preceding section. However, the presentation of the data and subsequent discussion will be aligned to main categories namely: (1) extraction of information from the document analysis and (2) the respondent views on the questionnaire. This presentation format is expected to enable coherence and streamlining of the data emerging from diverse data sources.

The examinations of the report indicate that the indirect costs of accident are not captured as per with the pre-set theme. This was clearly shown from the reports examined. Evidence suggests that there is no coordinated effort from the management of the organisations to do so. The practical implication of this is that the contractors will be short- 
changed in knowing the exact loss they incur and at the same time will not know how to curb the effect which will adversely affect the sustainability of the firm. The reason behind it can be attributed to the findings from the study (see table 4) as it relate to difficulty in extracting the information, organizational will, construction practitioners don't make use of the data and no justification of such exercise which Haupt and Pillay (2016) concurred as dominating factor responsible of such negligence. In resolving this issue of capturing indirect cost authors such as Levitt and Samelson, (1987); Okorie and Smallwood (2010) and Griffin (2006) propounded that within the study pre-set theme that the value of each cost item is derived as follows: overtime cost should be derived from the records of the personnel management and the payroll records using the actual scales of income for each worker involved for number of days actually lost; cost involved in administrating paperwork for incident investigation and reports should be derived from corporate health and safety department in the particular organisation or any unit saddled with such responsibility; cost of orientating the new workers should be derived from the records of either temporary employment services or technical related and the same rates as employees of organisation were used; cost resulting from delays should be captured from the records of personnel department; additional supervision cost should be derived from personnel department; cost of all the medical supports should be established from medical records kept by the various organisations; cost of productivity should be gathered from the personnel department and the payroll records of each workers; cost of cleaning up accident should be obtain from the medical records kept by the various organisations; cost associates with replacing material, plant and equipment should be derived from hire fees or replacement costs, depending on type of equipment and plant, since these costs are captured by each site (Levitt and Samelson, 1987; Okorie and Smallwood, 2010; Griffin, 2006). Also, the wider implication of this finding and as well as assertion made by the authors is that the capturing of indirect cost clearly deserves attention and can be captured amongst the stakeholders because such practice adds value to construction contractor business sustainability.

In probing the reason behind the findings, the study revealed many factors such as;difficulty in extracting the information; organizational will; construction practitioners don't make use of the data; no justification of such exercise; financial resources to carry out such task and technical know-how played a major role amongst the emerging contractors. Importantly, this factor indicates the severity of their influence on the capturing of the indirect cost of accident. These findings corroborate with the study of ILO (2011); Alkilani et al (2013) and Haupt and Pillay (2016) as it relates to the finding. This has an implication as the negligence hampers on the contractor's accountability and profitability. The provision for capturing indirect cost should be a pre-requisite for overall construction sustainability (Choi, 2006; Western National Insurance, 2010). Determination of indirect cost of accident as per each project will assist in identifying control measures that can be put in place to prevent further re-occurrences (Chileshe and Dzisi, 2012). Also it is a good-practice to document the outcome of any incident investigation to the rest of the employees, as that way they are all made aware of the potential risks (direct cost and indirect cost) and of changes the business has made to a process or procedure, including the reasons behind those changes (Choi, 2006; Watson 2017). In addition, Watson (2017) concurred that timely and efficient reporting of accident is needful to assess the financial risk and identify appropriate corrective actions that can be taken in engendering construction project accountability.In enhancing the condition, the study highlighted the factors such as; making it as a policy for any accident report to capture indirect cost; assigning timeliness on when the data must be captured in any accidents; training provision for personnel in charge for capturing such cost and improving the use of such records in decision making in the organisation. 


\section{IMPLICATION OF FINDINGS OF THE STUDY}

The study's findings will serve as a theoretical platform for the development of a framework for enabling effective capturing of indirect costs by the contractors in their accident reports. Also, the findings will assist stakeholders to have a comprehensive view of the factors that are hindering the capture of indirect cost of accident and factors that can enhance the conditions. It offers a knowledge base for industry stakeholders and especially the emerging contractors regarding the indirect cost of accident as it affects contractor's competitiveness.

\section{CONCLUSION}

Based on the study, it is paramount that the emerging contractors should understand the need to capture indirect cost of accident in their accident report. The need is necessary at this era as the industry is geared towards sustainable development. It is evident in the examined report that the economic impact of indirect cost cannot be established and as such will affect the accountability of the project performance. In the study, the authors highlight the need for a comprehensive analysis of the indirect cost of any construction-related accident. Such examination will deepen the debate surrounding indirect cost of accident which is neglected as the study deduced.

In furtherance to the study, there is a need for; establishment of indirect cost of accident in any report; a verifiable data; improvement of H\&S records; identifying an appropriate methodology to collect data on indirect cost of accident. The examination of these variables will add up to overall project performance in enhancing improved allocation of resources in construction accident abatement. It is expected that this study would provide the muchneeded debate surrounding the factors that hinder the capturing of indirect cost of accident and its improvement. This will bring about enthronement of best practices across board which leads to the establishment of robust OHS culture and sustainability of construction industry as a whole. The limitation of the study is relatively due to smaller sample adopted and therefore, the study is recommending a wider sample that will cut across all contractors. Thisstudy has practical implications on the emerging contractors as it provides information on factors that negate and impact on sustainability of the emerging contractors as it relates to OHS performance and competitiveness.

\section{REFERENCES}

Agumba, J. N and Haupt, T. C (2018). The influence of health and safety practices on health and safety performance outcomes in small and medium enterprise projects in the South African construction industry. J. S. Afr. Inst. Civ. Eng., Midrand, 60 (3), 61-72, Sept. 2018. Available from $<$ http://www.scielo.org.za/scielo.php?script=sci_arttextand pid=S102 120192018000300006and $\operatorname{lng}=$ enandnrm $=$ iso $>$. [Accessed on 21 February 2020].

Alkilani, S. Z., Jupp, J and Sawhney, A. (2013). Issues of construction health and safety in developing countries: A case of Jordan. Australasian Journal of Construction Economics and Building 13(3),141-156

Argenti, J. (1976). Corporate planning and corporate collapse. Long Range Planning, 9(6): $12-17$

Ayodele, E.O. and Alabi, O.M. (2011). Abandonment of Construction Projects in Nigeria causes and Effects. Journal of Emerging Trends in Economics and Management Science, 2(2), 142-145

Brace C.L. and Gibb, A.G.F. (2005). A health management process for the construction industry. In Haupt, T. and Smallwood, J. (Eds.) Rethinking and revitalising construction safety, health and quality. Port Elizabeth, South Africa.

Brauer, L.R. (2006). Safety and health for engineers, 2nd ed. New Jersey: Wiley-Inter science, 
Chileshe, N., and Dzisi, E. (2012). Benefits and barriers of construction health and safety management (HSM). Journal of Engineering, Design and Technology, 10 (2), 276-298.

Choi, S.D. (2006). A survey of the safety roles and costs of injuries in the roofing contracting industry. Journal of SH\&E Research, 3(1), 1-20.

Construction Health and Safety Group. (2018). Health and safety in the UK construction industry. Available from www.chsg.co.uk/news/health-and-safety[Accesed on 22/1/2020].

Construction Industry Development Board (2015). Framework: National Contractor Development Programme. Pretoria: CIDB.

Dainty, A.R.J. (2008). Methodological pluralism in construction management research, In: Knight, A. and Roddock, L. (Eds). Advanced research methods in the built environment, oxford: willey-Blackwell, pp.1-3

Department of Trade and Industry. (2004). Annual Review of Small Business in South Africa 2003. Pretoria: Department of Trade and Industry, Enterprise Development Unit.

Eyiah, A. K (2001). An integrated approach to financing small contractors in developing countries: A conceptual model. Construction Management and Economics, 19(5): 511518.

Federated Employer's Mutual Assurance Company. (2016). Injury and accident statistics. Available from http://www.fem.co.za/Layer_SL/FEM_HomeAccident_Stats/FEM_AccidentStats.ht $\mathrm{m}[$ Accesed on 22/2/2020].

Flin, R. (2003). Danger-men at Work: Management influence on Safety, Human Factors and Ergonomics in Manufacturing, Engineering Construction and management, 12 (2), 104 $-131$

Gambatese, J.A. (2008). Research issues in Prevention through Design. Journal of Safety Research, 39 (2), 153-156

Giang, D. T. H. and Pheng, L. S. (2011). Role of construction in economic development: Review of key concepts in the past 40 years. Habitat International, 35(1),118-125.

Griffin, J. (2006). The true cost of accidents - Underground construction. In Proceedings of the 49th ASC Annual International Conference, Charles Berryman, 2013.

Haupt, T. C and Pillay, K. (2016). Investigating the true cost of Construction Accident. Journal of Engineering, Design and Technology, 14(2), 373-419

Heinrich, H.W (1959). Industrial accident prevention: A scientific approach. New York: McGraw-Hill Book Co.

Hinze, J. (2006). Construction safety (2nd ed.). Upper Saddle River, NJ: Prentice-Hall Book.

Hinze, J. W. (2007). Construction safety, New Jersey: Prentice-Hall.

Hughes, P. and Ferrett, E. D. (2010). Introduction to Health and Safety in Construction, Butterworth Heinemann, Elsevier Linacre House, Jordan Hill Oxford OX2 8DP, UK.

Hughes, P., and Ferrett, E. (2016). Introduction to health and safety at work (6th ed.). New York, NY: Routledge

International Labour organisation. (2018). Standard on occupational safety and health promoting safe and healthy working environment: Geneva, ILO.

International Labour organisation (2011). ILO standard on occupational safety and health promoting safe and healthy working environment: Geneva, ILO

International Safety Equipment Association (ISEA). (2012). Personal protective equipment: An investment in your workers' and company's future. Arlington, VA: Author.

Kanchana, S., Sivaprakash, P., and Joseph, S. (2017). Studies on labour safety in construction sites. The Scientific World Journal, 2015, 1-6.

Kheni, N., Dainty, A. G. F., and Gibb, A. R. J. (2008). Health and safety management in developing countries: A study of construction SMEs in Ghana. Construction Management and Economics, 26 (11), 1159-1169. 
Laufer, A. and Ledbetter, W.B. (2016). Assessment of safety performance measures at construction sites. Journal of Construction Engineering, 112(4), 530-542.

Levit, R.E., and Samelson, N. M. (1987). Construction Safety Management, McGraw-Hill Book Company.

Lim, E.C. and J. Alum., Construction productivity: issues encountered by contractors in Singapore. International Journal of Project Management vol 13(1), 51-8, 2015.

Lingard, H. (2013). Occupational health and safety in the construction industry. Construction Management and Economics, 31 (6), 505-514.

Lutchman, C., Maharaj, R. and Ghanem, W. (2012). Safety management: A comprehensive approach to developing a sustainable system, 1st Edition, Boca Raton: CRC Press.

Manuele, F. (2011). Accident Costs: Rethinking ratios of indirect to direct costs. Available at https://aeasseincludes.assp.org/professionalsafety/pastissues/056/01/039_047_F2M anuele_0111Z.pdf[Accesed on 4/6/2020].

Murie, F. (2007). Building safety: An international perspective. International Journal of Occupational and Environmental Health, 13, 5-11.

Muzondo, F.T and Mc-Cutcheon, R.T. (2018). The relationship between project performance of emerging contractors in government infrastructure projects and their experience and technical qualifications. Journal of the South African Institution of Civil Engineering, 60(4), 25-33.

Nemaenzhe, P. P. (2010). Retrospective analysis of failure causes in South African small businesses. PhD Thesis, Pretoria: University of Pretoria.

Okorafor, C, Emuze, F.A and Das, D. K. (2016). Relative importance of health and safety performance evaluation factors in organisation level within Gauteng construction industry. In: Proceedings of the International Conference on Infrastructural Development in Africa Johannesburg.

Okorie, N. V., and Smallwood, J. J. (2010, July 18-20). Impact of health and safety culture on construction site performance in South-Africa. In Proceedings 5th Built Environment Conference (pp. 497-508). Durban

Okoye, P. U., Ezeokonkwo, J. U., and Ezeokoli, F. O. (2016). Building construction workers' health and safety knowledge and compliance on site. Journal of Safety Engineering, 5 (1), 17-26.

Okoye, P. U., Okolie, K. C., and Ngwu, C. (2017). Multilevel safety intervention implementation strategies for Nigeria construction industry. Journal of Construction Engineering, 2017, 1-14.

Orji, S. E., Enebe, E. C., and Onoh, F. E. (2016). Accidents in building construction sites in Nigeria: A case of Enugu State. International Journal of Innovative Research and Development, 5 (4), 244-248

Osei, V. (2013). The construction industry and its linkages to the Ghanaian economy Policies to improve the sector's performance. International Journal of Development and Economic Sustainability, 1(1), 56-72.

Peacock, R. (2000). Failure and assistance of small firms. Small Enterprise Series, 1: 1-56.

Pretorius, M. (2009). Defining business decline, failure and turnaround: A content analysis. South African Journal of Entrepreneurship and Small Business Management, 2(1), 116.

Raftery, J. (2003). Risk analysis in project management. S.l: Routledge.

Sanchez, F. A. S., Peláez, C. G. I., and Alís, J. C. (2017). Occupational safety and health in construction: A review of applications and trends. Industrial Health. National Institute of Occupational. Safety and Health, 55 (3), 210-218.

Shepherd, D. A., Wiklund, J and Haynie, J. M. (2009). Moving forward: Balancing the financial and emotional costs of business failure. Journal of Business Venturing, 24(2), 134-148. 
Siemiatycki, M. (2009). Academics and Auditors Comparing Perspectives on Transportation Project Cost Overruns. Journal of Planning Education and Research, 29(2), 142-156.

Smallwood J and Haupt T. (2005). The need for construction health and safety (Hand S) and the Construction Regulations: engineer's perceptions. Journal of the South African Institution of Civil Engineering, 47 (2), 2-8.

Smallwood, J and Emuze, F. (2016). Towards Zero Fatalities, Injuries, and Disease in Construction. Procedia Engineering, 164, 453-460

Statistics South Africa. (2018a). Gross domestic product: Second quarter. Statistical Release P0441. Pretoria: Statistics South Africa.

Statistics South Africa. (2018b). Quarterly labour force survey: Quarter 4. Statistical release P0211. Pretoria: Statistics South Africa.

Sukamolson, S. (2005). Fundamentals of Quantitative Research. Chulalongkorn University, Thailand.

Sutrisna, M. (2009). Research methodology in doctoral research: Understanding the meaning of conducting qualitative research, Working Paper presented in ARCOM Doctoral Workshop, Liverpool, John Moores University.

Temtime, Z.T and Pansiri, J (2004). Small business critical success/failure factors in developing economies: SME evidence from Botswana. American Journal of Applied Sciences, 1(1), 18-25.

United States OSHA. (2017). Safety and health management systems eTool: Costs of accidents. Washington, DC: U.S.

Van Eeden, S, Viviers, S and Venter, D. (2003). A comparative study of selected problems encountered by small businesses in the Nelson Mandela, Cape Town and Egoli metropoles. Management Dynamics, 12(3), 13-23.

Van Witteloostujin, A. (1998). Bridging behavioural and economic theories of decline: Organizational inertia, strategic competition, and chronic failure. Management Science, $44(4), 501-519$.

Watterson A. (2017). Global construction health and safety - what works, what does not, and why? International Journal of Occupational Environment and Health. 2017. 13,14.

Western National Insurance (2010). The total costs of accidents and how they affect your profits. Available at www.wnins.com/resources/commer cial/Spotlight/Total\%20cost\%20of\%20accidents.pdf [Accessed on 4/6/2020].

World Health Organisation. (2010). World Health Report 2010, Geneva: London. 